\title{
Temporal dimensions of knowledge exchanges in horizontal
}

\section{knowledge networks}

\begin{abstract}
Purpose - This study examines reciprocal exchanges in knowledge networks using temporal differentiation of knowledge exchanges. To date research on horizontal knowledge networks rather overlooks the temporal perspective, which could explain the dynamics of exchange in those networks.
\end{abstract}

Design/methodology/approach - The paper reports on a study of four horizontal knowledge networks in the UK over a period of 18 months.

Findings - The findings integrate three temporal dimensions of timescale, timeliness and time modalities. The dimensions have implications for the way knowledge is exchanged (or not), which can in turn sustain or stymie productive knowledge exchange in horizontal knowledge networks.

Originality - This study contributes to the knowledge management literature by providing a temporal perspective to understand reciprocal knowledge exchanges in horizontal knowledge networks.

Research limitations/implications - The study encourages researchers to attend to the micro-processes of knowledge exchanges through the integrative framework of temporalities. It seeks to inspire practitioners to appreciate how the impacts of knowledge networks play out in/over time, and how more effective coopetitive knowledge-sharing environments can be created and sustained by taking differentiated time structures into account.

Keywords: knowledge exchange, temporality, knowledge networks, reciprocity 1 


\section{Introduction}

There has been a growing line of inquiry into knowledge exchange in horizontal industry networks (Guercini \& Medlin, 2020; Sarala, Junni, Cooper, \& Tarba, 2016; Shi, Zhang, \& Zheng, 2019), in addition to the realisation of benefits from these networks (e.g. access to knowledge and resources that otherwise are inaccessible) (Balle, Steffen, Curado, \& Oliveira, 2019; Botelho, 2018; Sedighi, Lukosch, Brazier, Hamedi, \& van Beers, 2018). This increase in research reflects three main complexities pertaining to such networks. Firstly, unlike market and hierarchical networks that treat knowledge as an asset, horizontal industry networks treat it as an interaction, in which case the focus of network function shifts to the social interaction, dialectical negotiation and reciprocal exchanges (Dooley \& Gubbins, 2019; Eapen \& Krishnan, 2019). Secondly, from a structural perspective, these networks; (1) may not restrict access to join, (2) are neither sanctioned nor hierarchical, (3) are socially connected than organisationally, and (4) provide voluntary attendance or participation (Hacker, Bodendorf, \& Lorenz, 2017; Tasselli, Zappa, \& Lomi, 2020). Consequently, traditional management approaches to manage knowledge become limited and may become dysfunctional. Finally, blurriness of boundaries and volatility of relationships raise concerns over trust, knowledge accumulation, and social capital (Bai, Liu, \& Zhou, 2020; Cappiello, Giordani, \& Visentin, 2020).

A wide spectrum of research studies on knowledge exchange in horizontal knowledge networks show growing recognition of the innovative pathways these networks offer, in addition to the implications that forms of exchange have on how knowledge is created, 2 
acquired, and appropriated (Del Giudice \& Maggioni, 2014; Maghssudipour, Lazzeretti, \& Capone, 2020; Tallman \& Chacar, 2011). Examples of these studies that have broaden our understanding of knowledge exchange in networks include: the role of organisational culture (Ahammad, Tarba, Liu, \& Glaister, 2016; Fiedler, Casey, \& Fath, 2020) and intentions (Hwang, Lin, \& Shin, 2018; Kauppila, Rajala, \& Jyrämä, 2011) to share knowledge across borders; how innovative ideas are transmitted and activities are co-ordinated (Matricano, Candelo, Sorrentino, \& Martínez-Martínez, 2019; Peters, Pressey, \& Johnston, 2017); the role of reciprocal exchange in advancing knowledge exchange (or otherwise) in homogeneous networks (Baker \& Bulkley, 2014; Caimo \& Lomi, 2015) and competitive networks (Botelho, 2018). Orientation to open innovation and agility (Oliva \& Kotabe, 2019; Oliva, Couto, Santos, \& Bresciani, 2019) and the role of trust as a relational condition to explain why collaboration evolves (or not) over time (Galati \& Bigliardi, 2019) are also factors.

Despite the contributions these studies have made in the field of knowledge exchange, they have dealt with time mostly as a linear phenomenon in which these exchanges occur. As such, we seek to advance understanding of knowledge exchange by examining the temporalities of them for five main reasons. First, there has been growing criticism of linear time as a reductionist approach compared to temporalities (a multi-dimensional approach) in which knowledge exchange can be seen not passing through time but as constant construction and reconstruction of meanings, by the sensitive engagement with plurality of, for example, time (e.g. duration, timeliness, timing, etc) and space (e.g. interconnectedness, co-location, etc) (Bakker, DeFillippi, Schwab, \& Sydow, 2016; Berends \& Antonacopoulou, 2014). 
Second, similar to linear time, from a temporal perspective, knowledge exchange might be viewed as a continuity; however, contrary to linear time, it is a continuity that is established by reflecting upon the past to explore the future while continuously reinterpreting the present (Dawson \& Sykes, 2019). This entails complexities imbued by interests and power that are manifested in abandoning parts of the past intentionally (e.g. unlearning) or accidentally (e.g. forgetting) while amplifying others (Klammer \& Gueldenberg, 2019). Third, temporalities condition knowledge exchange as an ongoing process which allows it to manifest the agential role of network members through temporal contingencies that articulate not only the future but also the past as differentiated memories (Nyberg, Wright, \& Kirk, 2020). Fourth, the value of knowledge can be differentiated through temporal conditioning. In a linear view, knowledge exchange is deemed as extant or obsolete whereas taking various dimensions of time, the exchange can be viewed as synchronous, asynchronous, futuristic, fast, etc. Fifth, and finally, practitioners can make sense of various temporalities to think about knowledge network design, arrangement, and organisation. As such, practitioners can use the temporal dimensions as a measure of the value of knowledge and the network.

To sum up, we argue that viewing knowledge exchange through temporal perspective broadens our understanding of knowledge exchange as it relocates our view of knowledge differentials as a trade-off to manage into a paradoxical tension to embrace (e.g. in the case of competitor networks) (Botelho, 2018).

Our paper attempts a contribution that is both rigorous and relevant (Hodgkinson and Rousseau, 2009) by considering both a theoretical and practical problem when formulating the research questions and positioning the contributions (Nicholson et al., 2018). According 
to Nicholson et al.'s (2018) contribution conceptual framework, this paper makes an incremental contribution, which is measured against what knowledge already exists and by developing further what is currently known. In this study, we respond to recent calls for a more longitudinal approach that addresses the temporal perspective in examining knowledge exchanges in horizontal knowledge networks (Agostini, Nosella, Sarala Riikka, Spender, \& Wegner, 2019; Clegg, Josserand, Mehra, \& Pitsis, 2016; Dawson \& Sykes, 2019; Heracleous \& Bartunek, 2020; Nyberg et al., 2020). The central question here is: How do reciprocal exchanges influence knowledge exchange in a network over time? To answer this question, two sub-questions are raised: i) how do reciprocal knowledge exchanges occur over time in a horizontal knowledge network?; and ii) how these exchanges implicate upon the ways horizontal knowledge networks are created and sustained?

\section{Knowledge sharing in a coopetitive environment: A focus on reciprocal exchanges in horizontal industry networks}

Coopetition is described as a paradoxical relationship between two or more actors engaged in a number of interactions both cooperative and competitive, regardless of whether their relationship is horizontal or vertical (Bengtsson \& Kock, 2014). Nevertheless, there are a number of particularities in horizontal network relationships. First, unlike the more internationally-oriented vertical counterparts, horizontal networks often occur through local interactions where the aim of information exchange tends to be for mutual benefit (Ryan, Evers, Smith, \& Andersson, 2019). Ideas and knowledge exchange contribute to building social capital of these localised horizontal networks (Chiffoleau et al., 2019; Moschitz, and Oehen, B, 2020). Second, in knowledge exchange within a horizontal network, it is 
imperative to examine how individuals from competitor firms come together to share knowledge in what Broadhead (2020:6, cf. Spencer 2017) termed as "a long term, iterative, process through multiple interactions over time $[\ldots]$ for a more intense process of exchange". Third, in such networks, inter-organizational relations are often framed through interpersonal interactions (Grote, 2012), facilitated by a lead network manager (Mueller, 2012) to drive knowledge sharing through the network. Fourth, network members often exhibit higher levels of "caring and sharing" in order to leverage the social capital (Ryan et al., 2019). Reciprocity itself resides in the conditions of cooperation, whilst maximizing reflection in the learning context (Liu, et al 2020). Yet, this awareness of cooperation can also be strengthened when under the pressure of competition and mutual interests of the localised network. For example, Liu, et al. (2020, p. 356) found that "'the most effective organizational learning is under the flux of cooperation and competition, rather than any idealized forms, such as pure competition or pure cooperation". Whilst the majority of previous studies have tended to assume that knowledge sharing does not happen between competitors due to the opportunity costs in terms of time and loss of strategic advantage, there has been over the last twenty years a growing body of scholarship that acknowledges the coopetitive environment that horizontal knowledge networks create where individuals come together to simultaneously cooperate and compete (see e.g. Ghobadi and D'Ambra, 2012; Botelho, 2018).

In such a context, competitors often have similar knowledge resources that make it easier in principle to share knowledge. In order to facilitate access to valuable resources, social network theory is one way of nurturing the knowledge sharing connections, focusing on the existing limitations of organizational techniques by specifically creating organizational structures that underpin the work relationships and supporting processes (Poleacovschi, 
Javernick-Will, \& Tong, 2017). Researchers have found that those with strong ties tend to find it easier to exchange knowledge, especially in terms of tacit knowledge which is often difficult to articulate in writing (Hansen, 2002, Poleacovschi et al., 2017, Bouncken and Aslam, 2019). At the same time, such knowledge exchange is not without social costs; apart from well-reiterated concerns of the ability to put aside time for knowledge sharing, research has also shown that knowledge exchanges between competitor organisations can lead to the feeling of vulnerability of giving away and losing one's knowledge (c.f. Cabrera and Cabrera, 2002; Ritala et al., 2018), which often requires higher levels of trust and continued familiarity (Poleacovschi et al., 2017). Indeed, the question of who owns the knowledge asset, and in turn the associated competitive advantage, can be even more acute in horizontal knowledge networks where multiple competitive organisations come together to exchange information (Chan et al., 2005; Botelho, 2018). Indeed, when individuals within a network are known to exploit knowledge opportunistically for one's own career gains, members of the network have been found to be less willing to share knowledge (Serenko and Bontis, 2016).

Thus, studies have focussed on reciprocal exchanges in knowledge sharing in horizontal knowledge networks. For instance, Muthusamy and White (2005) found that reciprocal commitment, measured in terms of a ratio between a firm's level of committed resources and the perceived level of resources committed by others, and trust, had a direct and positive impact on knowledge exchange outcomes in an interorganisational alliance context. More recently, Levin and Walter (2019) found that trust, rather than structural concerns such as interaction frequency, is a key mechanism for members of a network to unlock the value of novel knowledge. 
Despite these insights, studies have tended to be cross-sectional (i.e. examined at a point in time). While the scope for studying how networks evolve over time (c.f. Borgatti and Halgin, 2011) and the need for longitudinal studies (c.f. Muthusamy and White, 2005) have been recognised, more needs to be done to qualitatively capture the dynamics of knowledge sharing in networks (c.f. Clegg et al., 2016). Nevertheless, knowledge is not distributed evenly in the network, and therefore the challenge is the ability to bridge those connections in the network, of those individuals central to the network (Poleacovschi et al, 2017). This requires a need to consider temporal dimensions, which will be elaborated in the next subsection.

Time matters in reciprocal exchanges: Timescales, timeliness and time modalities Time is a multi-faceted concept. Adam (1998) coined the term 'timescapes' to promote thinking beyond what she considered as industrial time, the quantitative, manufactured notions of time that are structured according to "a) the invariable beat of the clock, b) the economic commodification of time and c) the scientific use of time as a measure of abstract motion" (p. 11). While these three aspects of machine, economic and laboratory time provides a quantitative resource for manipulation and control, Adam (1998) argued that this obscures the more qualitative and contextual understanding of time, where "a symphony of rhythms and temporalities [...] underpins our development as humans as living organisms" (p. 13). Relating this symphony of rhythms to the context of learning in and across organisations, Rowe (2015) distinguished between planned (often top-down) quantitative time, against the more subjective and qualitative lived and imagined time, arguing that a broader perspective of time beyond industrial time can provide us with analytical "sensitivity regarding how established temporal rhythms shape sequences of action and reflection, also 
exploring how discontinuities in this sequencing can trigger collective reflection and action" (p. 107). Berends and Antonacopoulou (2014) reviewed the literature on organisational learning and its relationship with time and temporalities to identify an integrative framework that contains three key strands, which inspire our theoretical orientation. In what follows, we provide a salient explanation of the three strands, which we term as timescale, timeliness and time modalities.

Timescale: The first strand that Berends and Antonacopoulou (2014) identified was duration. This related to questions of whether there was sufficient (or insufficient) time to facilitate knowledge exchange, experimentation, reflection and learning. However, this sufficiency has less to do with a quantitative, linear understanding of time, and more with a qualitative, subjective experience of timescale. Lee and Sawyer (2010) stated: "time is more complex than a linear measure would suggest. Time has properties $[\ldots]$ concerned with norms, rules and conventions. To represent both, we use 'temporality' [...] to explain to others, and for others to make sense that one minute of time in a tender embrace with a loved one is experienced as 'shorter' than one minute of time with you stuck in an elevator" (p. 299). In an illustrative example of making a business case for investigating in sustainable technologies, the individual making the pitch to the financial decision-makers felt that the pitch only lasted seconds when the meeting had in fact run for hours (Chan et al., 2012: p. 503). Thus, the timescale allowed for knowledge exchange in a network context is often perceived as a qualitative and subjective experience of whether time (or rather, duration) is expanded or compressed, slow or speedy (see Holmqvist, 2009), and this can either help or hinder the process of knowledge exchange (Berends and Antonacopoulou, 2014). 
Timeliness: A second strand relates to timing, and this refers to when, in time, a particular event takes place (Berends and Antonacopoulou, 2014). Timeliness is the synchronisation of the reciprocal exchange and the environment. Reciprocity is essential for communities to support their member's professional development (Chia-An Tsiai and Kang, 2019). A previous study of knowledge sharing practices among investment professionals on a digital platform, Botelho (2018) questioned the proposition that the willingness of competitors to share knowledge depends on pre-existing relationships between them (i.e. strong tie) and that direct reciprocity can be expected. In a digital network environment, Botelho (2018) found that direct reciprocity cannot be expected all the time; instead, knowledge sharing is most likely to happen among competitors if they perceive that information that is shared - in this case, about potential market opportunities - is realised in a timely fashion. Put another way, when valuable and novel knowledge is exchanged and that this exchange is at a moment perceived to be most relevant at a given point in time, then this will encourage knowledge sharing. When information is given ahead of this moment or after, then the opposite holds.

Time modalities: For Berends and Antonacopoulou (2014), the third strand refers to orientations to the past, present and future. These orientations require a great deal of interpretation and imagination, as individuals make sense of historical information and speculate on future scenarios in the present moment. As Hibbert and Huxham (2011) argued, the possibilities of knowledge exchange are dependent on individual capacities for understanding and that this understanding is conditioned by past experience and organisational traditions. Through an ethnographic study of three horizontal knowledge networks, Hibbert and Huxham (2011) found that past traditions are not simply passively 
preserved, but actively imagined and reimagined in dialogue with others including those from outside the networks.

Based on our review of previous studies on knowledge exchange in horizontal networks and the limitations pertinent to pure quantitative views of time in knowledge exchanges, it is argued that the over-simplification of the concept of time in these exchanges leaves a gap in our understanding of the dynamics of knowledge exchange. In the next section, the research design will be elaborated to explain how the richer, multifaceted aspects of temporalities of knowledge exchanges in horizontal networks are examined in this study.

\section{Research design}

We examined reciprocal knowledge exchanges between participants of four horizontal knowledge networks. These 'network participants' are defined as representatives from various competitor organisations who voluntarily joined and attended events organised in these networks, whether occasionally or frequently. Participants who have a regular subscription and join for the purpose of explorative learning (Holmqvist, 2009) are thus known as 'network members'. The process-oriented focus in our study is on the lived experiences of network participants and members of the knowledge exchanges that take place in these networks. Our examination of the temporalities of reciprocal knowledge exchanges was informed primarily by interviews and supplemented by observations carried out over an 18-month period. The unit of analysis is individuals in networks who join the network to exchange knowledge with others in the form of reciprocal exchanges. On reciprocity, research on networks is often driven by quantitative analysis that focus mainly on the size and structure of networks; such studies simply describe the network at a moment of time 
(Berthod et al., 2017) which reduces the possibilities of accounting for the agency and what really happens in these networks (Clegg et al., 2016).

\section{Data site}

Data was collected from four knowledge networks located in the North West England (See

Table I). These networks were chosen because they were established horizontal networks that allowed an examination of reciprocal knowledge exchange as social interactions over time (cf. Spencer, 2017; Dooley \& Gubbins, 2019; Eapen \& Krishnan, 2019, and; Broadhead, 2020). The networks included the Manchester Media Network, Liverpool Media Network, Health Product Network and Women Entrepreneurs Network (all are pseudonyms). The Manchester and Liverpool Media Network were formed in 1998 and 2009 respectively by a group of passionate photographers who used to meet in a social setting. Both networks share the same ethos but are separate entities though. For example, local pubs in both Manchester and Liverpool were used to discuss the issues of the day and the needs of photography professionals (including photographers, photography journal editors etc.) in the respective cities. As the network grew, a decision was made in 2009 to split the network into two to provide a better service for photography professionals in each city. The two networks thus provided space for participants to share experiences and opportunities available such as the availability of dark rooms for processing photographs. At the time of the study, host regular (e.g. monthly networking events) networking events that facilitate knowledge exchange among members and between them and the public.

The Women Entrepreneurs Network is a network that brings together businesswomen and female entrepreneurs from the North West of England and provides a home for networking 
and marketing. The network was co-founded in 2008 in Greater Manchester by a Dane who previously worked for 16 years as a marketing consultant in several international companies. The idea for setting up the group occurred whilst she studied in Manchester; around that time, she wanted to establish a new business that offered support to female entrepreneurs, as well as utilise her skills.

The Health Products Network is a network of small companies manufacturing and selling health products based in Manchester. The network focused on providing guidance and advice to small businesses. The group was established in 2009 by three healthcare marketing professionals in Manchester.

$$
<<\text { Insert Table I here >> }
$$

\section{Data collection}

Data was collected over a period of 18 months through 53 hours non-participant observations and semi-structured interviews (see Table 1 below). The observations were based on the first author attending 23 networking events. The observations were captured in field notes that were written up immediately after each event. The fieldnotes captured the date, time and place of observed network, descriptions of the networking events observed, recording reflections of what went on, critical incidents that occurred, who were involved, and casual conversations with network participants regarding their experiences and feelings about the event. The observations were critical in enabling the first author to experience first-hand the interactions and reciprocal knowledge exchanges in these networks. The observations were also instrumental in corroborating the findings from the interviews with 36 individuals from 20 organisations participating across the four horizontal knowledge networks. To find patterns across the sets of data, the first author extensively discussed the observation results 
with the co-authors. The long discussions have been useful to preserving the voice of participants during the interpretation process of data analysis and to ensure we "grasped" the insider's perspective (Barley \& Kunda, 2001).

The interviews revolved around a number of key questions, including the interviewees' professional and career histories, how and why they came to know about, join and maintain participation in the network, their key experiences of participating in the network and how these have changed over time, and what and how they perceived they were getting from the networks through reciprocal knowledge exchanges. The interviews were recorded, amounting to 42 hours and 34 minutes of audio recordings that were then transcribed verbatim. The shortest interview lasted for half an hour while the longest was three hours. The average duration of interviews was an hour and twenty minutes. Thus, in line with qualitative research, the focus was not to find causal relationships, but to deepen the understanding of how and why things happen as they do (Berthod et al., 2017) in the four horizontal knowledge networks studied. The interviews were guided by a semi-structured protocol (Table XX), which included matters around the general background of the individual and the organisation represented, reasons for joining the network, perceived benefits (or disbenefits) from the networks, and how each interviewee perceived they were getting new knowledge out of the network (i.e. reciprocal knowledge exchange). Interviewees were also asked to reflect on the impacts of their participation in the network to the organisation they represented.

$<<$ Insert Table II here >> 


\section{Data analysis}

The transcripts of the semi-structured interviews and observational fieldnotes were analysed following a two-step approach. First, we openly coded the textual data line by line as we made sense of what the research participants meant in the descriptions of their lived experiences with the horizontal knowledge networks studied. In answering the overarching and sub-research questions, the analysis identified the research participants' reasons for joining and engaging with the respective networks, their perspectives of what contributed to the effectiveness (or ineffectiveness) of these networks, and their narratives of reciprocal knowledge exchanges in these networks. Thus, the open coding allowed the research team to build interpretations from the individuals whom we interviewed (Miles et al., 2013), assuming that meanings are constructed from what individuals experience rather than what they know (Berthod et al., 2017).

Second, we situated our participants' perspectives and experiences of participating in the networks within the different temporal dimensions of timescales, timeliness and time modalities to identify patterns of how these affected reciprocal knowledge exchanges, whether directly or indirectly. From these a priori dimensions, finer-grained analytical codes were produced from the textual data so that different paces (timescale), synchronicity (timeliness) and temporal orientation (time modalities) of reciprocal knowledge exchanges and their impacts could be detected (see Table III below). Thus, in line with Miles et al. (2013), we first produced descriptive and interpretive codes from line-by-line reading of the data, followed by finding pattern codes that enabled us to make inferences and explanations through higher-level, more abstract and aggregate categories. NVivo 12 was used to facilitate the analytical process; apart from aiding the organisation of the coding of the data, 
NVivo 12 was found to be most appropriate in enabling the synthesis of data from multiple sources (Howell Major and Savin-Baden, 2010). Furthermore, by making possible the analysis of a range of different media (e.g. textual transcripts from the interviews, memos and notes from the observational fieldwork, audio recordings), qualitative research analytical software like NVivo also allows for the preservation of the participants' voice (Parameswaran et al., 2020).

$<<$ Insert Table III here. $>>$

\section{Findings}

In this section, the findings are structured along the three aspects of timescale (duration), timeliness and time modalities to bring to the fore the temporal dimensions that shape how network participants engaged and reciprocated through knowledge exchange with other network participants.

\section{Timescale (Duration)}

Duration is more of a qualitative experience than it is just a quantitative measure of time (see Lee and Sawyer, 2010; Chan, 2012; Berends and Antonacopoulou, 2014). As shown in Figure 1 above, our participants reported three different lived experiences of duration, namely perceptions of time as moving too quickly, too slowly, or appropriate. While two individuals may share the same quantitative amount of time at a networking event, their experiences can be remarkably different. This is the case for Participants B2 and B4 who, despite spending the same two-hour session at a networking event, went away with very different outcomes. Participant B4 was able to share his experiences of working on a recent project with Participant B2 who did not think there has been valuable knowledge gained. 
Reciprocal knowledge exchange (or the lack thereof) can shape one's perception and lived experience of time as expanded, compressed or just about right. For example, perceiving that they are learning new knowledge from interacting with others during a networking event, Participants A3, B1 and C4 felt that the timescale provided was too rushed. When describing a session lasting an hour and a half, Participant C4 thought that it is difficult to "bounce ideas in 15-minute sessions". On the contrary, when participants felt they did not get anything substantial out of the interactions, they started to count the opportunity costs of attending the networking event. Such opportunity costs did not just relate to lost business opportunities, but also personal relationships since networking events can, at times, be organised outside of standard office hours. Like Participant D5 who talked about sacrificing family time with her husband and newborn, Participant C5 also talked about how she stopped going to early morning breakfast meetings because she no longer enjoyed the time spent at these meetings:

"I mean a lot of people pay 500 pounds, I can't remember, for B2Bs or whatever they call them [breakfast meetings], get up at 6 o'clock in the morning every week. No, I've done that for twelve years, and I don't want to do that again, it was too much like hmm like being at work. I do work, but I like to enjoy my work."

Due to the horizontal knowledge networks being relatively small, and attracting mainly participants from small-to-medium-sized enterprises (SMEs), our participants reported that the networks studied tend to be organised in a fairly informal way. Occasionally, facilitated sessions are run, for example when a guest speaker is invited to give a talk or when there is a facilitated skills-matching session to orchestrate conversations and relationships between problem-seekers and problem-solvers. Given how each participant's qualitative experience of duration can affect the perceived value they receive from the exchanges during networking sessions, it is therefore important to consider how the structure of the network, not only in terms of frequency of meetings and position of key members but also in how networking 
events are structured, can provide a participant's feeling of time well spent. However, trying to organise an event that is perceived by everyone to be 'just about right' in terms of timing is not so straightforward. As Participant A4 recalls from a skills-matching event that was deliberately compressed, where a problem-seeker was given just five minutes to describe the problem and its context with no interruption:

"[the organisers] made you four or five minutes you didn't think about yourself, you are concentrating on somebody else's problems, on somebody else his business and using your own experiences and your own expertise and situation that you know from yourself and from others, and helping somebody else and this was really a good feeling."

Thus, what this quote suggests is that opportunities for reciprocal knowledge exchange, where the scope of sharing problems and enabling other participants to give something back, are critical in shaping one's experience and perception of time well spent. In this example from Participant A4, despite having what may seem like a compressed 5-minute pitch by the problem-seeker, the facilitation of the session and the requirement of 'no interruption' were vital so that chances of achieving reciprocal knowledge exchange are maximised.

\section{Timeliness}

The timeliness of knowledge exchange was found to be a critical aspect of reciprocal knowledge exchanges in the four horizontal knowledge networks. Timeliness played out in two main possibilities. On the one hand, our participants noted the importance of synchronous learning, that is, reciprocal exchanges that take place in time (Berends and Antonacopoulou, 2014).

As Participant B9 explained,

"[...] so here is the book, it's a distance learning course, that's rubbish actually for me it is. I learn best by reflecting on things with people, so [...] the bulk of the learning was delivered through getting the group together, so here are the themes, here are the issues, what your experiences, what are your 
thoughts, let's explore those together. And those were really good structured forms for me to think about my learning to date in the context of my contemporaries, so like-minded consultants and like-minded businesses.

For Participant B9, learning through the academic route meant that context was taken out of the learning process (see Rowe, 2015; Gibb et al., 2017). By contrast, learning with his peers within a given space (i.e. at the networking event) and in a moment in time was critical. When asked about why they joined the particular network, common reasons raised by all our participants included the desire to find new business or employment opportunities, sell new products, benchmark one's performance and knowledge base against their peers, and learn new problem-solving techniques. For the first three reasons, our participants indicated that there is an immediacy to knowledge exchange that takes place in networking events. As Participant C10 remarked,

"So they can get more business, that's the whole purpose at the end of the day, you know you go to networks to make connections so you can build your business, that is the core function."

Participant B5 also described a transactional approach to networking, as he argued that participants should not be coy about the need to get mutual benefits out of attending networking events.

"I feel that and I don't know if this is a British thing, awkwardness about networking between two businesses and saying, 'Look, I have this to sell, do you want to buy it?' or 'I am looking to buy something, have you got something I want to buy?' And I felt there was an awkwardness about that and this is kind of like forced relationship [...] but I don't think you should be ashamed the reason to be there is business."

Participant B5 also commented that the proliferation of online social networks (e.g. Twitter and LinkedIn) also meant that connecting with others can be much more instantaneous than attending conventional face-to-face networking events. Here again, the opportunity cost of attending networking events was raised as a concern as he noted that a two-hour event soon becomes a day lost when travelling time is added, and this can equate to a quite substantial 19 
cost to business. Thus, the ability to get timely benefits, whether in terms of new business/work or learning new techniques and developments in the marketplace, is an important consideration.

Nevertheless, not all reciprocal exchanges are synchronous. As seen in Figure 2 above, the benefits of networking events can play out in asynchronous ways too. The quote from Participant C2, for instance, illustrate the notion of six degrees of separation (Milgram, 1967) where participants within a network can also reach out to others beyond the network through acquaintances from fellow participants. Yet, timeliness also plays a part here for the acquaintances to connect in practical terms. Our participants described the follow-up work that needed to be done to sustain connections made during networking events. In one example, there also had to be a chance (or timely opportunity) for reciprocal knowledge exchanges to go further and beyond the networking event, as Participant C3 explained:

"I often will meet one-on-one with somebody initially, and then there is more often not an event, in the diary that you can say, 'If you are interested in hearing anymore either we can meet up again [...] or we have got Nina coming up from London, on such and such a day, we're holding a presentation, if you would like to come along and listen to some more, then this is where it is, this is the time."

Nevertheless, the timeliness of reciprocal exchanges in our networks is not always immediate. For some, the networking experience was considered a "slow process" (Participant A8), where relationships are built up informally over a long period of time requiring a participant to attend events regularly. Others like Participant C9 regarded those who wanted an instantaneous reciprocal exchange in networks as examples of "really bad networking in that people who are very pushy, they are sales focused and they are not really interested in people". The women we interviewed also regarded different approaches to networking as being a gendered practice, with Participant $\mathrm{C} 4$ referring to those wanting 
immediate gains as "old school networking", and Participant D2 considering that such a transactional approach to be "a very male approach to the networking and it's very much about what I do instead of what can I do for you".

Of the four common reasons for joining a network, there was recognition by our participants that the learning of new problem-solving techniques tended to take a bit more time. Here, our participants differentiated between tacit and explicit knowledge and recognised that while it is easy to hear about new developments in the marketplace at networking events, applying such knowledge is another matter. Thus, direct copying of techniques is not always possible since there is a need to relate any new technique to the specific problem context. As Participant C5 explained,

"Unless you are a photographer and somebody copies and puts your image and puts their name on it then that's a fraud. I mean, I've been working around, look at close and you get ideas, you don't copy them exactly, you know you stylise them in your style if you like, you make something people say, 'Oh, you've got style, you can tell your work just from looking at it'

It is worth qualifying here that the four networks studied are relatively small in scale, often connecting individuals from SMEs. While these may be competitors in their respective fields, it is interesting to note how participants have regarded other network members as 'experts' that can facilitate their own personal development and learning. This perhaps explains why Participant C5 raised the more tacit issue of style.

\section{Time modalities: Past, present and future orientations}

The third dimension deals with time modalities. These refer to an individual's orientation towards the past, present or future. Our findings suggest that the orientation that one takes can influence the ways and pace of reciprocal knowledge exchanges. Thus, those who are more present-oriented tend to want quick wins, such as making contacts to secure new work 
(Participant D1) or benchmarking one's knowledge base or performance against other peers (Participant C9). As already mentioned, not every participant sees the opportunities of networking in the present. For many of our participants, networks provide them with developing possible futures often in terms of new and improved ways of working by applying knowledge gained through a contact or at an event. Those with a future orientation are also prepared to challenge the status quo of doing business. For instance, Participant D2 argued that

"there is a real change happening in the business world in general and I see it across say even going into the corporate world. People are becoming much more socially aware, becoming much more conscious about the impact that they have on the world as such and I think that people are desiring to be more ethical and to be more authentic and more caring in the way they do business and it is, they are very much part of what our small businesses are about."

Thus, Participant D2 has a view of a more ethical future where businesses exist not (just) to make money but also to make a difference and wider impacts on society. This future vision influences the ways she forms her identity within the small business network and shapes her engagement with the network activities. Giving something back is also what can legitimise and sustain one's participation in a network.

For example, Participant A5 recounted how he had been attending talks organised by a photography network, but it was not until he returned the favour by giving a talk that he finally felt that he belonged to the network:

"[...] they have a photographer come, show their work, talk about their work and then have a kind of QandA and so I went to a couple of those, saw photographers' work, talked to them, talked to other people who were there at the meetings and quite often we have a kind of social thing afterwards where we go to the pub or something like that and just kind of slowly, slowly built up through there. When I came back from my second bout of travelling, I did a talk at the [network] meeting where I showed some of my work and talked about my experiences travelling and then it just sort of snowballed from there I guess." 
Thus, this shows again that reciprocal knowledge exchange is a vital part of developing, growing and sustaining a network, and those participants who are more future-oriented tend to be in it for the long-haul. This is in contrast to those networks that are more transactional in nature. For instance, Participant A1 contrasted his experiences with two networks, and even though he did get new work through the more transactional network, he quickly lost interest in that network because it lacked the feeling of being part of something bigger:

"I decided I didn't want to do any more free work for [Network A]. I didn't feel particularly valued by them. I went to do volunteer work thinking - not the last festival but the one before - they were just totally chaotic and I'd turn up at a place to give up my free time [and they said,] 'We've already got the people we need, sorry you came down but we don't need anyone so just go home. I was kind of like I'm giving up my free time for this, you know, I actually have other things that I could be doing [...] Now as it turned out, I later got paid work from them but I would say the thing about [Network B] is that I feel like I'm part of the [Network B] family. You know.. I feel well connected to all the people that work there."

There are also participants who were past-oriented. For instance, Participant B5 talked about how a network he had been engaging with had changed in its profile, and where those members that he used to associate with were no longer the same. Thus, the decline in the number of kindred spirits can often alienate individuals, which resulted in him leaving the network.

Such alienation was also found in Participant A2 who recalled how he struggled to fit in a very specific network that specialised in Chinese photography:

"[...] initially when I entered into the group, I was seen as an outsider because of being born in the UK, non Mandarin speaker, so there's a real sort of reservation of 'why is he here and why have we invited, you know, not one of our own?' And, erm, there would always be the occasional dropping into Mandarin language or Cantonese language during the discussion and that was almost like it felt at times that they're hiding things and they're talking about why's he here sort of thing" 
Not daunted by the experience, and in part due to his interest in the Chinese culture, he decided to take up a course in the Mandarin language so he could fit in and get along with members. Indeed, we observed that those who tend to be past-oriented tend to be drawn to and cherish the history of the network. Nevertheless, it would be too simplistic to label individuals as falling into a single category of time modality. In reality, our participants criss-cross between past, present and future orientations even if they had a particular predisposition. As Adam (1998) argued, the relationship between past, present and future is socially embedded, and that organisations and individuals live in a past, present and future continuum. Looking at the past to reflect upon the unfamiliar experiences in the present, network participants make sense of and ascribe meanings to such experiences with a view of possible futures.

\section{Discussion}

In this paper, we responded to recent calls for taking a temporal perspective on learning and knowledge exchanges in networks (Berends and Antonacopoulou, 2014; Rowe, 2015; Clegg et al., 2016). By situating our analysis of temporal dimensions in the study of four horizontal networks, a context that is relatively under-examined when compared to studies of vertical networks (Barley et al., 2018), we also examined small-scale horizontal networks that comprise small-to-medium-sized enterprises. Thus, this focus on small-scale networks adds to existing research that has hitherto been dominated by analysis of large networks and organisations (Van Wijk et al., 2008; Konstantinou and Fincham, 2011; Botelho, 2018).

Three temporal dimensions have been found to shape and be shaped by knowledge exchanges in the networks studied, including the pace and rhythm (timescale), synchronicity (timeliness) 
and past, present and future orientations (time modalities) of knowledge exchange in networks. These temporal dimensions provide an insight into the dynamic processes of knowledge exchange in networks. While typologies have been produced to classify various trajectories of how knowledge exchange can be integrative or differentiated in networks (e.g. Barley et al., 2018), our findings add to these practitioner classifications by showing the influences of temporal perspectives in differing contexts. For example, we observed how individuals who have similar backgrounds and who share similar knowledge resources tend favour knowledge exchanges that are of a quicker tempo, more present-oriented and with the possibility of asynchronous learning (e.g. through further reading outside of the networking events). Conversely, those with differentiated knowledge resources have expressed a need to take the time to process new knowledge and explore ways of exploiting different knowledge domains in their practical problem context; these individuals have indicated a preference for more time in networking events to allow for synchronous learning and the exchange to be more productive during the networking event. Thus, how practitioners regard the timescale, timeliness and time modality in a network event is influenced by and influences the extent to which one is transactional (i.e. wanting a quick win now) or relational (i.e. willingness to build a long-term relationship) in the ways they exchange knowledge. Put another way, while one's perception of the degree of getting something back has been recognised as a key motivator for knowledge sharing (see Wasko and Faraj, 2005), the willingness for practitioners to reciprocate is also dependent on their temporal perspectives.

Studies on networks have tended to examine and emphasise the structural characteristics, particularly on and how the centrality and embeddedness of and strength of ties between actors can help or hinder the exchange of knowledge (e.g. Gulati, 1999; Borgatti and Halgin, 
2011; Hsu and Chang, 2014; Caimo and Lomi, 2015; Poleacovschi et al., 2017; Barley et al., 2018). The attributes of individual members (e.g. attitudes and competence) have also come under the spotlight (e.g. Endres and Chowdhury, 2019), while others explained how organisational characteristics (e.g. Balle et al., 2019) can influence knowledge exchange outcomes. By adding temporal dimensions to the analysis, a more nuanced understanding can be offered for practitioners as to how the attributes and characteristics of individual members and networks play out. For example, a critical factor in the literature is the importance of trust (see Hsu et al., 2007; 2014; Levin and Walter, 2019) in promoting knowledge exchange in networks. Our findings show that developing trust is in part also connected with practitioners time perspective. Those who were more present-oriented tended to indicate a motivation for using networking events as a trading zone for gaining quick wins (e.g. new business contacts and contracts, new employment opportunities) and thus were more transactional in developing fleeting relationships (see Konstantinou and Fincham, 2011). Conversely, practitioners who were more future-oriented were also more open about the kinds of relationships they were prepared to invest time in cultivating.

The types of knowledge exchanged also featured as a major point in our practitioner findings. Previous studies tended to distinguish between tacit and explicit knowledge, with scholars suggesting that it is easier and perhaps less risky to share explicit knowledge rather than tacit knowledge (Hansen, 2002; Becerra et al., 2008). Our findings suggest that temporal dimensions are also at play here. Given the time pressures of networking events, it is far easier for practitioners to exchange explicit knowledge, and that this can also be done asynchronously outside of networking events. On the other hand, tacit knowledge requires a process of sensemaking in order to contextualise learning to one's problem in practice. 
Therefore, exchanging tacit knowledge tends to benefit from synchronous, face-to-face learning-by-doing (see Gherardi, 2011), which requires a longer timescale. Thus, what is considered timely depends on the types of knowledge being exchanged. Botelho (2018) suggested that, in a network of competitors, knowledge sharing is reciprocated when timely information about the market is being exchanged. Whilst our practitioner based findings also show a certain degree of immediacy when it comes to the trading of market information, not all of our participants share this view of reciprocal knowledge exchanges in the networks studied. In the four horizontal networks studied, participants expressed a willingness to learn, perhaps due to the networks comprising small-to-medium-sized enterprises. Like Gibb's et al. (2017) participants, there is a recognition that individuals cannot survive alone and that there is a need to benchmark one's learning and performance against each other, and to support one another to learn and be competitive.

\section{Conclusion}

This study explores the temporalities of knowledge exchanges in horizonal industry networks. It focuses on the various temporal dimensions through which knowledge exchange unfolds and discusses how pertinent complexities within which the exchange takes place can be embraced than sought to disentangle. In doing so, the research makes an incremental contribution to knowledge (Nicholson, LaPlaca, Al-Abdin, Breese, \& Khan, 2018) by spotting a neglect in the literature of knowledge exchange and employing a temporal perspective to further deconstruct these exchanges. Therefore, the paper addresses two questions as follows: 
i) How do reciprocal knowledge exchanges occur over time in a horizontal knowledge network?

Through four networks, we shine a spotlight on temporal dimensions of timescale, timeliness and time modalities, and argue that appreciating these dimensions as multi-faceted can enable an understanding of the multiple ways in which individuals experience knowledge exchange and the way they perceive the gains (or the lack thereof) of these exchanges. The subjective view of how time is perceived to be compressed, expanded or just appropriate (timescale); the preference for synchronous and asynchronous learning (timeliness) and one's past, present or future orientation (time modality) can influence the level of engagement or detachment from networks. Thus, this has practical implications not only for the structural characteristics of the networks, but also for the ways of structuring the networking events and beyond.

Our paper therefore makes a number of contributions. First, we contribute to theory by providing a broader understanding of reciprocal knowledge exchange using temporal dynamics and orientations. Extant literature has voiced the importance of the norms of reciprocity in transactional ways, but this has neglected how temporal perspectives can also shape the relational aspects of networks and networking. By detailing the three dimensions of timescale, timeliness and time modalities, our second contribution is to inform researchers on knowledge exchange of the significance of considering a multidimensional perspective of time in which case they trace how network members reflect on the past to make sense of the future in their everyday practice. A third contribution is made towards research methodologies. Temporal research can be developed using longitudinal research that takes into account the situated nature of knowledge exchange. For example, researchers could 
design their research to capture knowledge exchanges as they unfold and therefore research design should be consistent with the duration, timing and time modalities of the relevant research setting (e.g. network or organisation). This inherently means decision on when to conduct the research, the frequency of interviews and observation and at point of time to ask research subjects to reflect on their past should be designed carefully and in line with knowledge exchange processes (Berends \& Antonacopoulou, 2014).

ii) How these exchanges implicate upon the ways horizontal knowledge networks are created and sustained?

A fourth contribution is to inform practice, via organisers of networks on how to create supportive environments that are inclusive of different temporal perspectives to maximise the effectiveness for exchanging knowledge and thereby sustaining networks. Our findings show the importance of providing negotiated time or accommodating time structures (for example, allowances for the duration, timing, pacing, and synchronicity of knowledge exchange events) rather than the fixed and non-negotiable structures for knowledge to be exchanged and for benefits to be reaped. The structures may, for example, be of short or long duration or rapid or slow pacing that allow for critical events to be discussed properly and to mitigate for the perception of urgency (or the lack of) that might impact the quality of knowledge exchanges. A fifth contribution, is to inform practice organisations on the various challenges (resistance to change, failure to capture relevant knowledge, failure to make sense of knowledge gained, etc) to knowledge exchange that they may have oversimplified due to discounting time to a single mode (passage of time) and to allow for such challenges to be treated at a multi-level basis (e.g. duration issues, timing issues, etc) 
There are several future research avenues that may result from this study. Our analysis was limited to three dimensions of time (timescale, timeliness and time modalities) so future research may tackle various aspects of temporality such as temporal homogeneity, temporal heterogeneity, temporal disjuncture and other dimensions of time (Heracleous \& Bartunek, 2020; Kunisch, Bartunek, Mueller, \& Huy, 2017) . It would be useful, for example, to study how individuals or even organisations in networks move between knowledge integration and knowledge differentiation taking into consideration the aforementioned dimensions of time. Another avenue for future research may focus on how different roles of individuals in a knowledge exchange network might be influenced by their temporal orientation. For example, research could focus on individuals' perception of past as an untapped experience and how this informs the sensemaking of uncertain future. Third, our findings shed light on the temporality of knowledge exchanges only, future research may focus on how temporality influences network antecedents and consequences and more specifically how expectations of participants in either way (antecedent/consequence) are shaped by participant's temporal orientation (e.g. past oriented). These would make defined contributions to both theory and practice.

\section{Funding}

This research did not receive any specific grant from funding agencies in the public, commercial, or not-for-profit sectors.

\section{References}

Adam, B. (1998) Timescapes of Modernity: The environment and invisible hazards, London: Routledge.

Agostini, L., Nosella, A., Sarala Riikka, M., Spender, J. C., \& Wegner, D. (2019). Editorial. Journal of knowledge management, 23(10), 2007-2015.

Ahammad, M. F., Tarba, S. Y., Liu, Y., \& Glaister, K. W. (2016). Knowledge transfer and cross-border acquisition performance: The impact of cultural distance and employee retention. International Business Review, 25(1, Part A), 66-75. 
Bai, W., Liu, R., \& Zhou, L. (2020). Enhancing the learning advantages of newness: The role of internal social capital in the international performance of young entrepreneurial firms. Journal of International Management, 26(2), 100733.

Baker, W. E., \& Bulkley, N. (2014). Paying it forward vs. rewarding reputation: Mechanisms of generalized reciprocity. Organization Science, 25(5), 1493-1510.

Bakker, R. M., DeFillippi, R. J., Schwab, A., \& Sydow, J. (2016). Temporary organizing: Promises, processes, problems. Organization Studies, 37(12), 1703-1719.

Balle, A. R., Steffen, M. O., Curado, C. \& Oliveira, M. (2019). Interorganizational knowledge sharing in a science and technology park: the use of knowledge sharing mechanisms. Journal of Knowledge Management, 23(10), 2016-2038.

Barley S. R., \& Kunda, G. (2001). Bringing Work Back In. Organization Science, 12(1), 7695

Barley, W. C., Treem, J. W. and Kuhn, T. (2018). Valuing multiple trajectories of knowledge: A critical review and agenda for knowledge management research, Academy of Management Annals, 12(1), 278-317.

Bengtsson M., Kock, S., (2014). Coopetition-Quo vadis? Past accomplishments and future challenges, Industrial Marketing Management, 43(2), 180-188.

Berends, H. and Antonacopoulou, E. (2014). Time and organizational learning: A review and agenda for future research, International Journal of Management Reviews, 16(4), 437453.

Berthod, O., Grothe-Hammer, M. and Sydow, J. (2017). Network ethnography: A mixedmethod approach for the study of practices in interorganizational settings, Organizational Research Methods, 20(2), 299-323.

Borgatti, S. P., \& Halgin, D. S. (2011). On network theory. Organization science, 22(5), $1168-1181$.

Botelho, T. L. (2018). Here's an opportunity: Knowledge sharing among competitors as a response to buy-in uncertainty, Organization Science, 29(6), 1033-1055.

Bouncken, R. \& Aslam, M. M. (2019). Understanding knowledge exchange processes among diverse users of coworking-spaces. Journal of Knowledge Management, 23(10), 20672085

Broadhead, J. (2020). Building inclusive cities: reflections from a knowledge exchange on the inclusion of newcomers by UK local authorities. Comparative Migration Studies, 8(1), 1-17.

Cabrera, A. and Cabrera, E. F. (2002). Knowledge-sharing dilemmas, Organization Studies, 23(5), 687-710.

Caimo, A. and Lomi, A. (2015). Knowledge sharing in organizations: A Bayesian analysis of the role of reciprocity and formal structure, Journal of Management, 41(2), 665-691.

Cappiello, G., Giordani, F., \& Visentin, M. (2020). Social capital and its effect on networked firm innovation and competitiveness. Industrial Marketing Management.

Chan P. W. (2012) Constructing a sense of time in projects: implications of a Bergsonian view of time, in: S. D. Smith (Ed.) Proceedings of the $28^{\text {th }}$ Annual ARCOM Conference, 3-5 September 2012, Edinburgh, UK, Association of Researchers in Construction Management, 497-507.

Chan, P., Cooper, R. and Tzortzopoulos, P. (2005). Organizational learning: conceptual challenges from a project perspective, Construction Management and Economics, 23(7), 747-756. 
Chia-An Tsai, J. and Kang, T.-C. (2019). 'Reciprocal intention in knowledge seeking: Examining social exchange theory in an online professional community', International Journal of Information Management, 48, pp. 161-174

Chiffoleau, Y., Millet-Amrani, S., Rossi, A., Rivera-Ferre, M. G. \& Merino, P. L. (2019). The Participatory Construction Of New Economic Models In Short Food Supply Chains. Journal Of Rural Studies, 68, 182-190.

Clegg, S., Josserand, E., Mehra, A., \& Pitsis, T. S. (2016). The transformative power of network dynamics: A research agenda. Organization Studies, 37(3), 277-291.

Dawson, P., \& Sykes, C. (2019). Concepts of time and temporality in the storytelling and sensemaking literatures: A review and critique. International Journal of Management Reviews, 21(1), 97-114.

Del Giudice, M. \& Maggioni, V. (2014). Managerial practices and operative directions of knowledge management within inter-firm networks: a global view. Journal of Knowledge Management, 18(5), 841-846

Dooley, L., \& Gubbins, C. (2019). Inter-organisational knowledge networks: synthesising dialectic tensions of university-industry knowledge discovery. Journal of knowledge management.

Eapen, A., \& Krishnan, R. (2019). Transferring tacit know-how: Do opportunism safeguards matter for firm boundary decisions? Organization Science, 30(4), 715-734.

Endres, M. L. and Chowdhury, S. (2019) Team and individual interactions with reciprocity in individual knowledge sharing, in: Effective Knowledge Management Systems in Modern Society, IGI Global, pp. 123-145.

Fiedler, A., Casey, C., \& Fath, B. (2020). Transnational employee voice and knowledge exchange in the multinational corporation: The European Company (SE) experience. Human Relations, 0018726720905351.

Galati, F., \& Bigliardi, B. (2019). Redesigning the model of the initiation and evolution of inter-firm knowledge transfer in R\&D relationships. Journal of knowledge management, 23(10), 2039-2066.

Gherardi, S. (2011). Organizational learning: The sociology of practice, In: M. EasterbySmith and M. A. Lyles (Eds.) The Blackwell Handbook of Organizational Learning and Knowledge Management, Chichester: John Wiley and Sons, pp.43-65.

Ghobadi, S. \& D'Ambra, J. (2012). Knowledge sharing in cross-functional teams: a coopetitive model. Journal of Knowledge Management, 16(2), 285-301

Gibb, J., Sune, A. and Albers, S. (2017). Network learning: Episodes of interorganizational learning towards a collective performance goal, European Management Journal, 35(1), 15-25.

Guercini, S., \& Medlin, C. J. (2020). A radical constructivist approach to boundaries in business network research. Industrial Marketing Management.

Gulati, R. (1999) Network location and learning: The influence of network resources and firm capabilities on alliance formation, Strategic Management Journal, 20(5), 397420.

Hacker, J. V., Bodendorf, F., \& Lorenz, P. (2017). A framework to identify knowledge actor roles in enterprise social networks. Journal of knowledge management.

Hansen, M. T. (2002). Knowledge networks: Explaining effective knowledge sharing in multiunit companies. Organization Science, 13(3), 232-248.

Heracleous, L., \& Bartunek, J. (2020). Organization change failure, deep structures and temporality: Appreciating Wonderland. Human Relations, 0018726720905361. 
Hibbert, P., \& Huxham, C. (2011). The carriage of tradition: Knowledge and its past in network contexts. Management Learning, 42(1), 7-24.

Hodgkinson, Gerard P., and Denise M. Rousseau. (2009), "Bridging the rigour-relevance gap in management research: It's already happening!." Journal of Management Studies Vol.46, No. 3, pp.534-546.

Holmqvist, M. (2009). Complicating the organization: A new prescription for the learning organization?, Management Learning, 40(3), 275-287.

Howell Major, C. and Savin-Baden, M. (2010). An Introduction to Qualitative Research Synthesis: Managing information explosion in social science research, Oxon: Routledge.

Hwang, Y., Lin, H., \& Shin, D. (2018). Knowledge system commitment and knowledge sharing intention: The role of personal information management motivation. International Journal of Information Management, 39, 220-227.

Kauppila, O.-P., Rajala, R., \& Jyrämä, A. (2011). Knowledge sharing through virtual teams across borders and boundaries. Management Learning, 42(4), 395-418.

Klammer, A., \& Gueldenberg, S. (2019). Unlearning and forgetting in organizations: a systematic review of literature. Journal of knowledge management.

Konstantinou, E. \& Fincham, R. (2011). Not sharing but trading: Applying a Maussian exchange framework to knowledge management. Human Relations, 64(6), 823-842.

Kunisch, S., Bartunek, J. M., Mueller, J., \& Huy, Q. N. (2017). Time in strategic change research. Academy of Management annals, 11(2), 1005-1064.

Lee, H. and Sawyer, S. (2010). Conceptualizing time, space and computing for work and organizing, Time and Society, 19(3), 293-317.

Levin, D. Z., \& Walter, J. (2019). Before they were ties: Predicting the value of brand-new connections. Journal of Management, 45(7), 2861-2890.

Liu, F, Wu, J, Huang, X \& Fong, PSW (2020), 'Impact of intra-group coopetitive incentives on the performance outcomes of knowledge sharing: evidence from a randomized experiment', Journal of knowledge management, 24.(2) 346-368

Maghssudipour, A., Lazzeretti, L., \& Capone, F. (2020). The role of multiple ties in knowledge networks: Complementarity in the Montefalco wine cluster. Industrial Marketing Management.

Matricano, D., Candelo, E., Sorrentino, M., \& Martínez-Martínez, A. (2019). Absorbing inbound knowledge within open innovation processes. The case of Fiat Chrysler Automobiles. Journal of knowledge management, 23(4), 786-807.

Miles, M. B., Huberman, A. M. \& Saldana, J. (2013). Qualitative data analysis, Sage.

Moschitz, H. And Oehen, B. (2020) 'Creating Value(S) By Integrating Local and Extra-Local Resources In Cereal Production In The Swiss Alps', International Journal of Sociology Of Agriculture \& Food, 26(1), Pp. 48-68

Mueller, E. (2012). How to manage networks? The role of network attributes and incentives in network governance. International Journal of Entrepreneurship and Small Business 9, 15(1), 57-75.

Muthusamy, S. K. and White, M. A. (2005) Learning and knowledge transfer in strategic alliances: A social exchange view, Organization Studies, 26(3), 415-441.

Nicholson, J. D., LaPlaca, P., Al-Abdin, A., Breese, R., \& Khan, Z. (2018). What do introduction sections tell us about the intent of scholarly work: A contribution on contributions. Industrial Marketing Management, 73, 206-219.

Nyberg, D., Wright, C., \& Kirk, J. (2020). Fracking the future: the temporal portability of frames in political contests. Organization Studies, 41(2), 175-196. 
Ogulin, R., Guzman, G. \& Nuwangi, S. M. (2020). Knowledge capabilities in supply chain networks: a taxonomy. Journal of Knowledge Management.

Oliva F. L., \& Kotabe, M. (2019). Barriers, practices, methods and knowledge management tools in startups. Journal of knowledge management, 23(9), 1838-1856.

Oliva, F. L., Couto, M. H. G., Santos, R. F., \& Bresciani, S. (2019). The integration between knowledge management and dynamic capabilities in agile organizations. Management Decision, 57(8), 1960-1979.

Parameswaran, U. D., Ozawa-Kirk, J. and Latendresse, G. (2020) To live (code) or to not: A new method for coding in qualitative research, Qualitative Social Work, 19(4), 630644.

Peters, L. D., Pressey, A. D., \& Johnston, W. J. (2017). Contagion and learning in business networks. Industrial Marketing Management, 61, 43-54.

Poleacovschi, C., Javernick-Will, A., \& Tong, T. (2017). The link between knowledge sharing connections and employee time savings: A social network analysis. Construction management and economics, 35(8-9), 455-467.

Ritala, P., Husted, K., Olander, H. and Michailova, S. (2018) External knowledge sharing and radical innovation: the downsides of uncontrolled openness, Journal of Knowledge Management, 22(5), 1104-1123.

Rowe, A. (2015) Exploring a spatial-temporal understanding of organizational learning. Management Learning, 46(1), 105-124.Ryan, P., Evers, N., Smith, A., \& Andersson, S. (2019). Local horizontal network membership for accelerated global market reach. International marketing review.

Sarala, R. M., Junni, P., Cooper, C. L., \& Tarba, S. Y. (2016). A sociocultural perspective on knowledge transfer in mergers and acquisitions. Journal of Management, 42(5), 12301249.

Sedighi, M., Lukosch, S., Brazier, F., Hamedi, M., \& van Beers, C. (2018). Multi-level knowledge sharing: the role of perceived benefits in different visibility levels of knowledge exchange. Journal of knowledge management.

Serenko, A. \& Bontis, N. (2016). Negotiate, reciprocate, or cooperate? The impact of exchange modes on inter-employee knowledge sharing. Journal of Knowledge Management, 20(4), 687-712

Shi, X., Zhang, Q. \& Zheng, Z. (2019). The double-edged sword of external search in collaboration networks: embeddedness in knowledge networks as moderators. Journal of Knowledge Management, 23(10), 2135-2160.

Spencer, S. (2017). The global exchange approach to knowledge exchange, Oxford: COMPAS https://www.compas.ox.ac.uk/wp-content/uploads/GEM-approach-toknowledge-exchange-paper-030417-1.pdf accessed 10th August 2020.

Tallman, S., \& Chacar, A. S. (2011). Communities, alliances, networks and knowledge in multinational firms: a micro-analytic framework. Journal of International Management, 17(3), 201-210.

Tasselli, S., Zappa, P., \& Lomi, A. (2020). Bridging Cultural Holes in Organizations: The Dynamic Structure of Social Networks and Organizational Vocabularies Within and Across Subunits. Organization Science.

Van Wijk, R., Jansen, J. J. and Lyles, M. A. (2008) Inter-and intra-organizational knowledge transfer: a meta-analytic review and assessment of its antecedents and consequences, Journal of Management Studies, 45(4), 830-853. 
Wasko, M. M. and Faraj, S. (2005) Why should I share? Examining social capital and knowledge contribution in electronic networks of practice, MIS Quarterly, 29(1), 3557. 